\title{
Study on the optimal design of volume fracturing for shale gas based on evaluating the fracturing effect-A case study on the Zhao Tong shale gas demonstration zone in Sichuan, China
}

\author{
Yongxue Lin ${ }^{1,3} \cdot$ Shanyong $\mathrm{Liu}^{1,2}$ (D) Shuyang Gao ${ }^{1,3} \cdot$ Yuan Yuan $^{4} \cdot$ Jia Wang $^{5} \cdot$ Siqi Xia $^{5}$
}

Received: 30 July 2020 / Accepted: 4 March 2021 / Published online: 18 March 2021

(c) The Author(s) 2021

\begin{abstract}
Hydraulic fracturing is the key technology in the development of shale gas reservoirs, and it mainly adopts volume fracturing technology to communicate hydraulic fractures with natural fractures to increase the drainage area. In view of the difficulty in characterizing the complex fractures created by multistaged fracturing in horizontal shale gas wells and the immaturity of fracturing optimization design methods, this study first evaluated the stimulation effect of fracturing technology based on treatment data and microseismic data. Then, the fracture characteristics after frac were considered, and a post-frac simulation was studied based on the discrete fracture network (DFN) model and the microseismic monitoring data as constraints. Finally, from the simulation results, an optimal design method of volume fracturing for shale gas was proposed based on the evaluation of the frac effects. The National Shale Gas Demonstration Zone in Zhaotong, Sichuan Basin was used as an example to study the optimal frac design of shale gas wells. The results show that (1) after optimizing the design, the optimal interval range is $50-70 \mathrm{~m}$, the liquid volume of a single stage is $1800-2200 \mathrm{~m}^{3}$, the amount of sand is $80 \mathrm{~m} \sim 120 \mathrm{t}$, and the slurry rate is $10-12 \mathrm{~m}^{3} / \mathrm{min}$. (2) Two different frac design schemes were implemented in two wells on the same platform, and the production of the optimized design scheme was $14.7 \%$ greater than the original scheme. Therefore, the frac optimization design based on evaluating the fracturing effect can better guide the development of subsequent shale gas wells in this area.
\end{abstract}

Keywords Shale gas $\cdot$ Microseismic monitoring $\cdot$ Hydraulic fracturing $\cdot$ Optimal design

\section{Introduction}

Shale gas is an unconventional oil and gas resource which hydrocarbon does not migrate compared to the convention reservoir. It is mainly located in high carbon shale and exists

Shanyong Liu

liushanyong@yangtzeu.edu.cn

1 State Key Laboratory of Shale Oil and Gas Enrichment Mechanism and Effective Development, Beijing 100101, China

2 Institute of Mud Logging Technology and Engineering, Yangtze University, Jingzhou 434023, Hubei, China

3 Sinopec Research Institute of Petroleum Engineering, Beijing 100101, China

4 Research Institute of Petroleum Exploration and Development, Petro China, Zhejiang Oilfield Company, Hangzhou 310023, Zhejiang, China

5 School of Geoscience, Yangtze University, Wuhan 430100, Hubei, China in adsorption or free state. Shale reservoirs have the physical characteristics of low porosity and low permeability, and economic productivity can only be obtained by hydraulic fracturing (Wu et al. 2012). Because of its huge potential production, shale gas has become a global energy resource of high interest. In addition to the successful development of shale gas in North America, China has also actively carried out research on technology and theory of shale gas exploitation. At present, three National Shale Gas Development Demonstration Zones have been established in the Sichuan Basin (Liang X et al. 2019). In contrast to the fracturing mode in conventional oil and gas reservoirs, shale gas reservoirs mainly adopt large-scale volume fracturing technology, which aims to form artificial fractures with high conductivity, communicate and expand natural fractures in the reservoir, create the largest fracture network volume in the shale reservoir, and increase production and the ultimate oil recovery from the shale gas wells (Liu S et al. 2018). Due to the complex geological conditions of shale reservoirs, reservoir stimulation is vastly different from that of conventional 
oil and gas wells, and many factors need to be considered; thus, optimizing the design of fracturing shale gas wells is more complex and difficult.

The design of shale fracturing is different from conventional fracturing in that a symmetrical double-wing fracture is formed (see Fig. 1 a), which mainly depends on predicting the productivity to optimize the geometric parameters and conductivity of the fracture network (see in Fig. 1 b). The productivity prediction models mainly include mathematical analytical models, the discrete fracture network (DFN) model and the double porous media model (Cheng Y et al. 2012). On this basis, scholars in China and abroad have carried out optimization research on the geometric parameters and conductivity of the fracture network. According to the studies of Warpinski et al. (2009) and Ge (2011), hydraulic fractures may be effective for shale gas reservoir development only if they have a certain conductivity. In the fracturing process, in addition to achieving a larger stimulation reservoir volume (SRV), it is also necessary to obtain a certain conductivity of the fracture network to improve the overall permeability in the stimulation zone. Guo (2015) established an equivalent high-permeability zone model based on the Warren-Root model and equivalent seepage theory. Cheng (2012) and Pan (2014) considered the influence of stress interference on the extension of fracture clusters, analyzed the screen outs that occurred while pumping the proppants or due to insufficient distribution of the fracture network, and provided a qualitative optimization method of cluster spacing. Roussel (2011) thought that multiple fractures may lead to stress interference to form a stress reversal area, which is regarded as the potential stimulation area of the reservoir, and used this as the optimization goal to quantitatively optimize the cluster spacing.

However, the accuracy of these analytical models is poor, the numerical simulation process is complex, and the precision requirement of the parameters is high; therefore, they are not convenient for field applications. At the same time, there are few mature methods for complex fracture characterization and field fracturing optimization design. Therefore, this study uses the National Shale Gas Demonstration Zone in Zhaotong as the study case, comprehensively considers the matching of geological characteristics and engineering parameters in this area, and evaluates the effect of combining fracturing with microseismic monitoring technology and a fracturing simulation method. A new, simple and practical fracturing design method was proposed based on evaluating the fracturing effect. The new method was applied to optimize the fracturing parameters in the study area, a case study of the treatment parameters optimization for a shale gas well was evaluated, and the effect of different sand addition processes was analyzed and evaluated by using the distribution characteristics of the microseismic events.

\section{Methodology}

\section{Background of the study area}

The YS block is located in the southern margin of the southern Sichuan low-steep fold zone of Taiao, Sichuan, adjacent to the northern Yunnan-Guizhou depression in the south. The sedimentary cover is approximately $6000 \mathrm{~m}$ to $7000 \mathrm{~m}$ thick from the Sinian to the Jurassic. The main sedimentary assemblages consist of marine facies and continental facies. Marine black shale is the main gas source rock in the study area. There is a thick layer from the Longmaxi formation of the Lower Silurian to the Wufeng formation of the Upper Ordovician, which has high abundance of organic carbon and good preservation and is the key target strata of this block (Luo $X$ et al. 2018). Figure 2 shows the stratigraphic column and structural map of the Longmaxi Formation in the YS block.

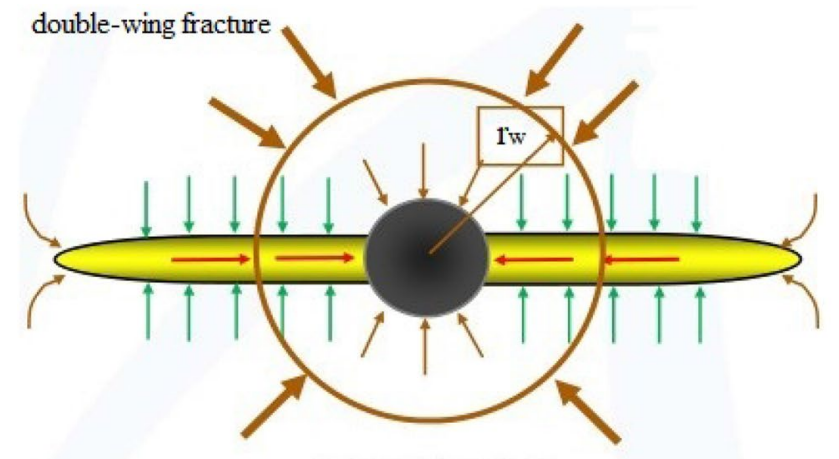

(a)

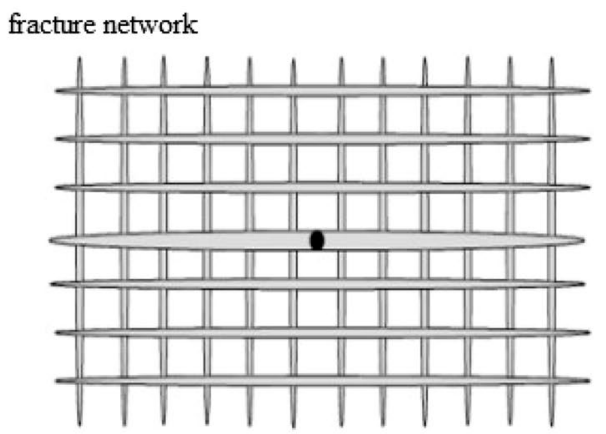

(b)

Fig. 1 Fracture geometry diagram of double-wing fracture (a) and fracture network (b)

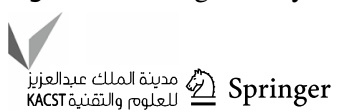



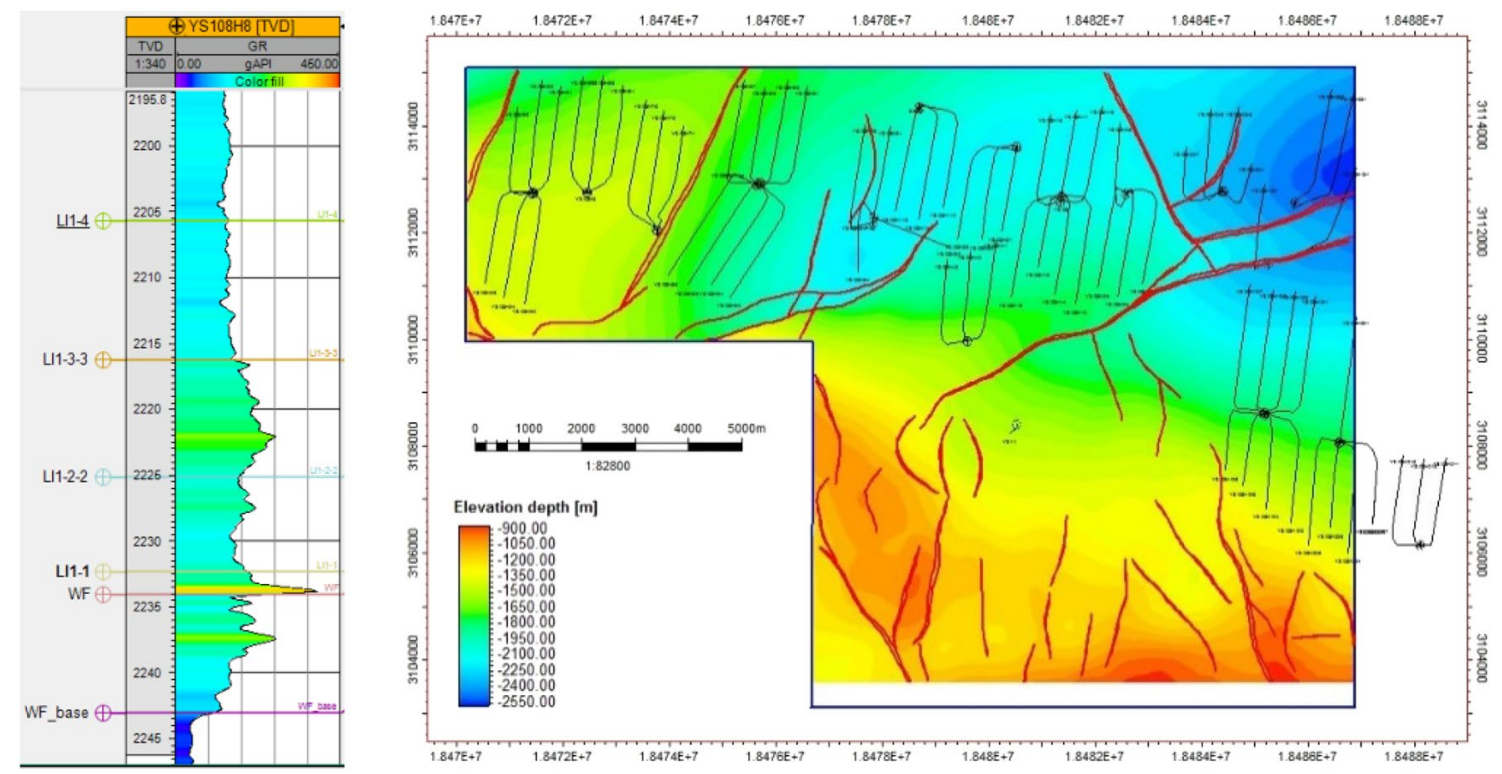

Fig. 2 Stratigraphic column and structural map of the Longmaxi Formation in the YS block

\section{Fracturing sand adding technology}

For shale gas, large-scale volume fracturing is the key to increasing well production. The fracturing design parameters include the wellbore structure, completion mode, perforation and fracture initiation mode, displacement, fracturing fluid and proppant performance, fluid volume, sand mass and so on. Studies show that the operational parameters have the greatest influence on the fracture network of volume fracturing and the SRV (Enriquez T et al. 2019).

In the early fracturing treatment in the YS block, one fracturing system was mainly adopted, which was slightly adjusted locally. The pump schedule design concept of each well was similar, using the same fracturing fluids and proppants: (1) The fracturing fluid adopted used a combination of slick water and linear gel, the pad and sand-carrying fluid used slick water ( $80 \%$ liquid volume) to communicate the hydraulic fractures and natural fractures as far as possible, and linear gel (20\%) was used in the flush stage to increase the sand concentration. (2) The sand pump schedule adopted a combination of 70/140 mesh ceramic powder and 30/70 mesh ceramsite, and medium or high strength ceramsite was used according to the closing stress. (3) The average interval between fracturing stages was $60-80 \mathrm{~m}$, and the average sand volume of a single section was $40-50 \mathrm{~m}^{3}$. (4) Acid was one kind of prefluid; on the one hand, it could solve the near wellbore damage issue, on the other hand, it could improve the longer-distance treatment effect and improve the effective SRV. (5) The pump time and amount of gel were adjusted to ensure the fracture's height extension and expansion on the plane, and a degradable temporary diverting agent was added in real-time to realize the inner turning of the crack.

Considering well $\mathrm{H}-1$ in the YS block as an example, the length of the horizontal section was $1189.9 \mathrm{~m}$ and the true vertical depth was $2546.6 \mathrm{~m}$. Fifteen stages were performed with plug and perf multistaged fracturing technology. The pump schedule adopted a combination mode of ceramic powder and ceramsite, the slurry was $7-10 \mathrm{~m}^{3} / \mathrm{min}$, and the average liquid volume of each stage was $2131.5 \mathrm{~m}^{3}$. At the beginning of stage 9 , it was found that the natural fracture zone of the remote limestone layer continued to develop, the liquid leakoff was serious, and it was difficult to add sand. Hence, for stage 10, the proportion of 100 mesh ceramic powder was increased to reduce the multicracks in the near wellbore. Table 1 shows the values of the main operating parameters of a typical fracturing section of the YS-1 well.

\section{Analysis of fracturing operation}

Considering H1-1 well in the YS block as an example, the fracturing treatment curve of a typical fracturing section was analyzed (as shown in Fig 3). The total liquid volume of the first stage was $2354.5 \mathrm{~m}^{3}$ and the sand mass was 104.5 tons. Ceramic powder and ceramsite were used, of which 9.6 tons of 70/140 mesh ceramic powder and 94.7 tons of 30/70 mesh ceramsite were used. The slurry was $8.0-9.5 \mathrm{~m}^{3} / \mathrm{min}$, the frac pressure was $68.5-83.4 \mathrm{MPa}$, and the frac process proceeded smoothly.

Figure 4 shows the results of monitoring the microseismic fracture of stage 1 . It was found that the operation started from the perforation position. The hydraulic

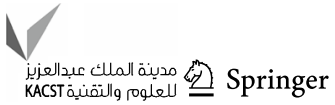


Table 1 Statistics of main treatment parameters of typical fracturing section in well H-1

\begin{tabular}{lllcll}
\hline Stage & $\begin{array}{l}70 / 140 \text { ceramic } \\
\text { powder(ton) }\end{array}$ & $30 / 70$ ceramsite(ton) & Fluids $\left(\mathrm{m}^{3}\right)$ & Slurry $\left(\mathrm{m}^{3} / \mathrm{min}\right)$ & Sand \\
\hline 1 & 9.6 & 94.7 & 2354.5 & 9.0 & Ceramic powder+ ceramsite \\
9 & 13.0 & 28.5 & 958.3 & 7.0 & Ceramic powder+ ceramsite + divert \\
10 & 12.9 & 47.9 & 1322.5 & 7.5 & $\begin{array}{c}\text { Ceramic powder+ ceramsite (increase } \\
\text { the concentration of ceramic } \\
\end{array}$ \\
& & & & powder) \\
\hline
\end{tabular}

Fig 3 The first stage of main fracturing construction curve

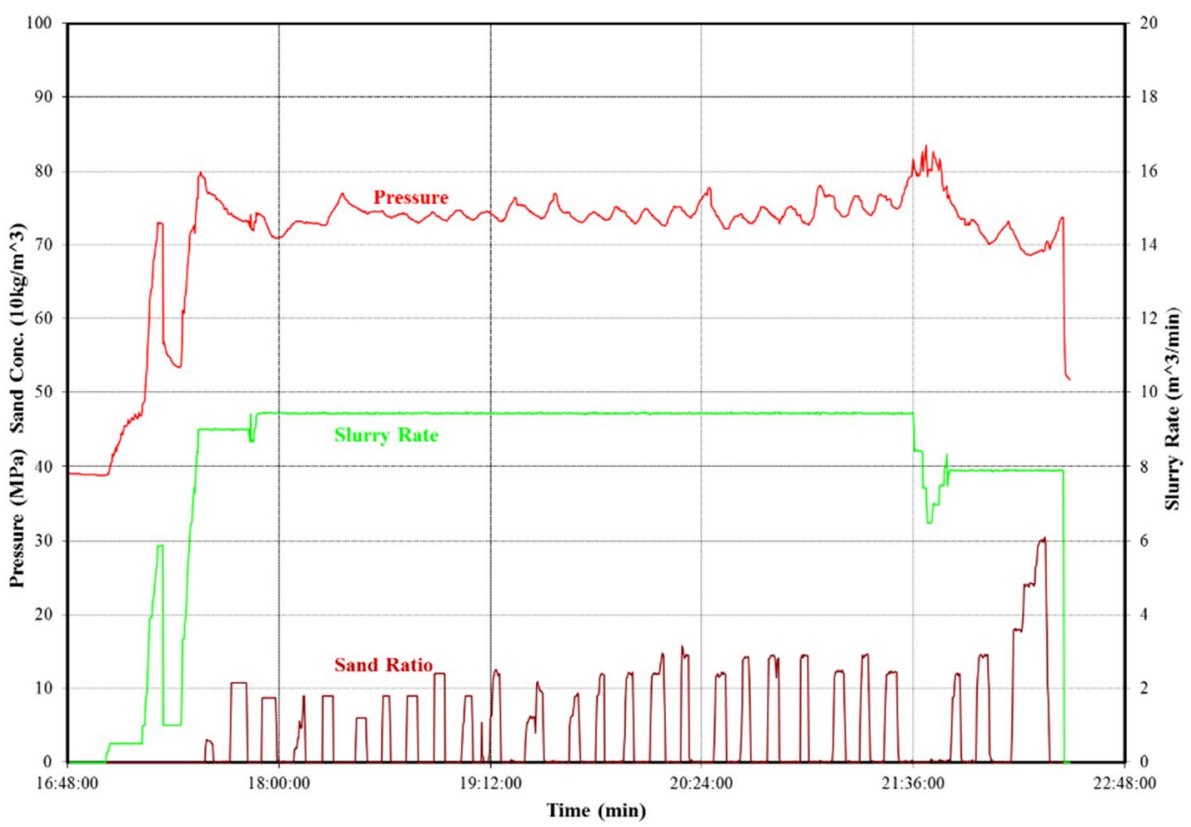

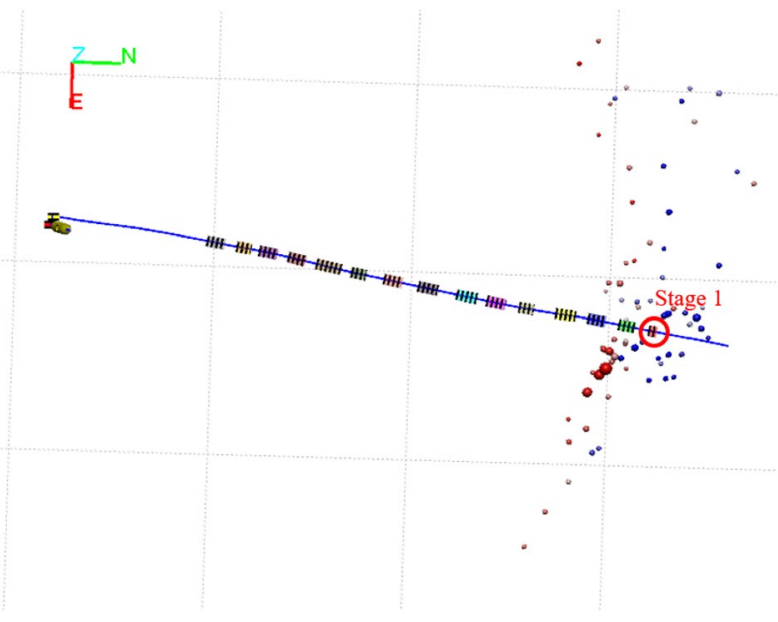

Fig. 4 Monitoring results of microseismic cracks of stage 1 (color code is displayed according to time)

fracture was approximately 1200 meters long, which was generally perpendicular to the wellbore trajectory, with a width of 100-300 meters and a vertical fracture height of approximately $30-50$ meters. The microseismic fracture monitoring results showed that the fracture geometry was good and the SRV was sufficient when the fracture was extended to the second stage.

Figure 5 is the fracturing treatment curve of stage 9 . At the beginning of the operation, it was found that the natural fracture zone of the remote limestone layer continued to develop, the liquid leakoff was serious, and it was difficult to add sand. A biodegradable fiber agent was used in the field to divert the crack. The plugging effect was obvious after adding the fiber, and the fracture entering the natural fracture zone was well-controlled. The first fiber turning was successful, and a new hydraulic fracture was opened on the other side of the wellbore.

Figure 6 is the microseismic monitoring result of stage 9. This section started from the perforation position and further communicated with the natural fracture. The plugging effect was obvious after adding the sand powder, and the fracturing fluid entering the natural fracture zone was well-controlled. Abnormally high pressure up to $94 \mathrm{MPa}$ occurred during the operation, making it difficult to add sand, and the fracturing was ended ahead of schedule. After the pump was stopped, 
Fig. 5 Treatment curve of stage 9

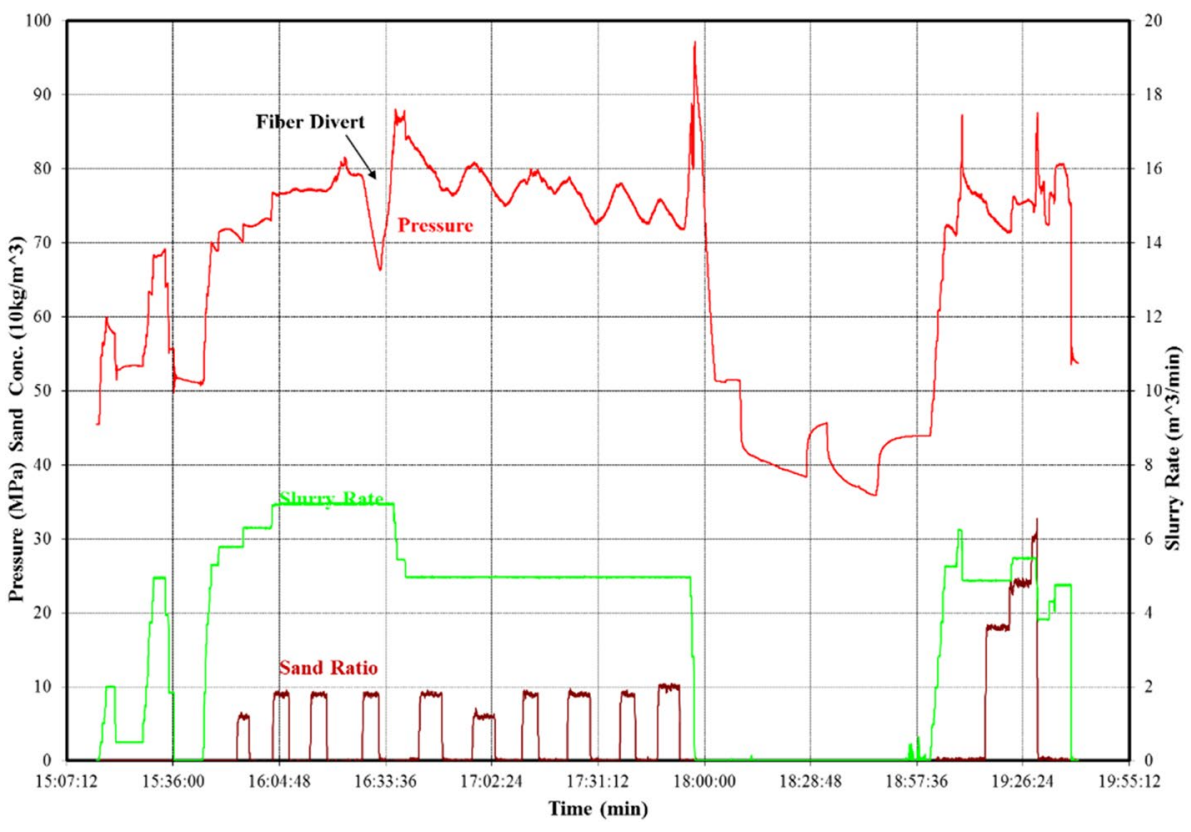

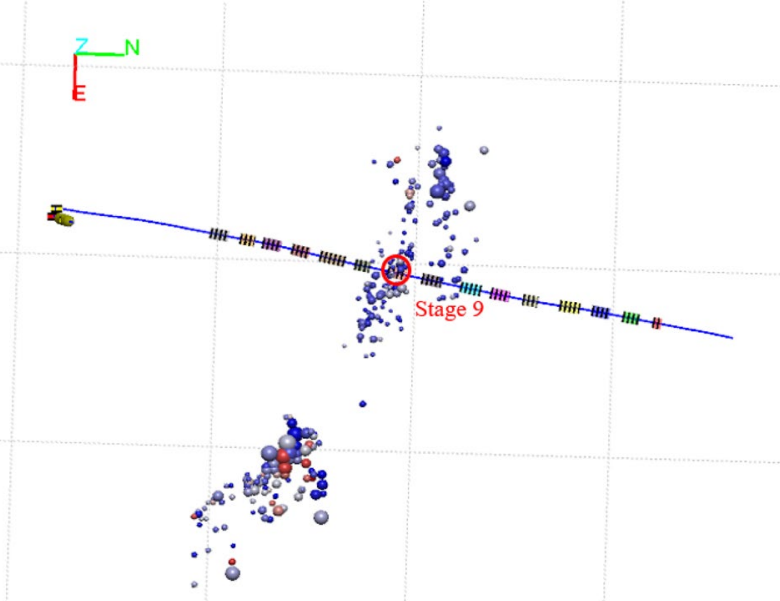

Fig. 6 Monitoring results of microseismic cracks of stage 9 (color code is displayed according to time)

the microseismic events in the natural fracture zone in the eastern part of the wellbore continued to develop. The fractures around the wellbore were approximately 600 meters long and 150 meters wide, crossing the area from stage 8 to stage 10 . The vertical fracture height was approximately 80-100 meters, and the fractures in the red circle developed further into the limestone layer, with a length of approximately 400 meters and a height of 30-50 meters.

For stage 10 (as shown in Fig. 7), when the operation was almost finished, it was found that a natural fracture zone of the limestone layer opened approximately 500 meters east of the wellbore, the filtration loss of the fracturing fluid was serious, and the treatment was greatly disturbed. To reduce the complexity of fractures in the near wellbore, the number of perforation clusters was changed from 3 to 2 , and the proportion of 100 mesh ceramic powder was increased in an attempt to block leakage and turns. The fracture started in the perforating section, and the pressure increased from $70 \mathrm{MPa}$ to $80 \mathrm{MPa}$ after slugging three 100-mesh ceramsite sections. Microseismic fracture monitoring showed that the fracture turned to the west of the wellbore and further opened, and new fracture zones formed at both ends of the wellbore.

As shown in Fig. 8, the microseismic monitoring results of magnitude 19 show that the section started from the perforation position and was well-isolated from the natural fracture zone. The pressure increased from $70 \mathrm{MPa}$ to $80 \mathrm{MPa}$ after three silty ceramic sections were plugged into the well, indicating that the fracture turned to the west of the wellbore and further opened, and new fracture zones formed at both ends of the wellbore. The fractures then developed toward natural fractures in the southeast, forming three roughly parallel natural fracture concentration zones, and had a further downward development trend. The three fracture zones were approximately 300-500 meters long and 40-60 meters high. After the pump was stopped, the microseismic events continued to develop in the three natural fracture zones. (Fig. 9)

\section{Analysis of distribution characteristics of microseismic}

A microseism is a small seismic event caused by rocks breaking due to a change in the stress field, and analyzing microseisms is one of the most effective methods to evaluate fracturing effects (Rascon E et al. 2018). During hydraulic 
Fig 7. Treatment curve of stage 10

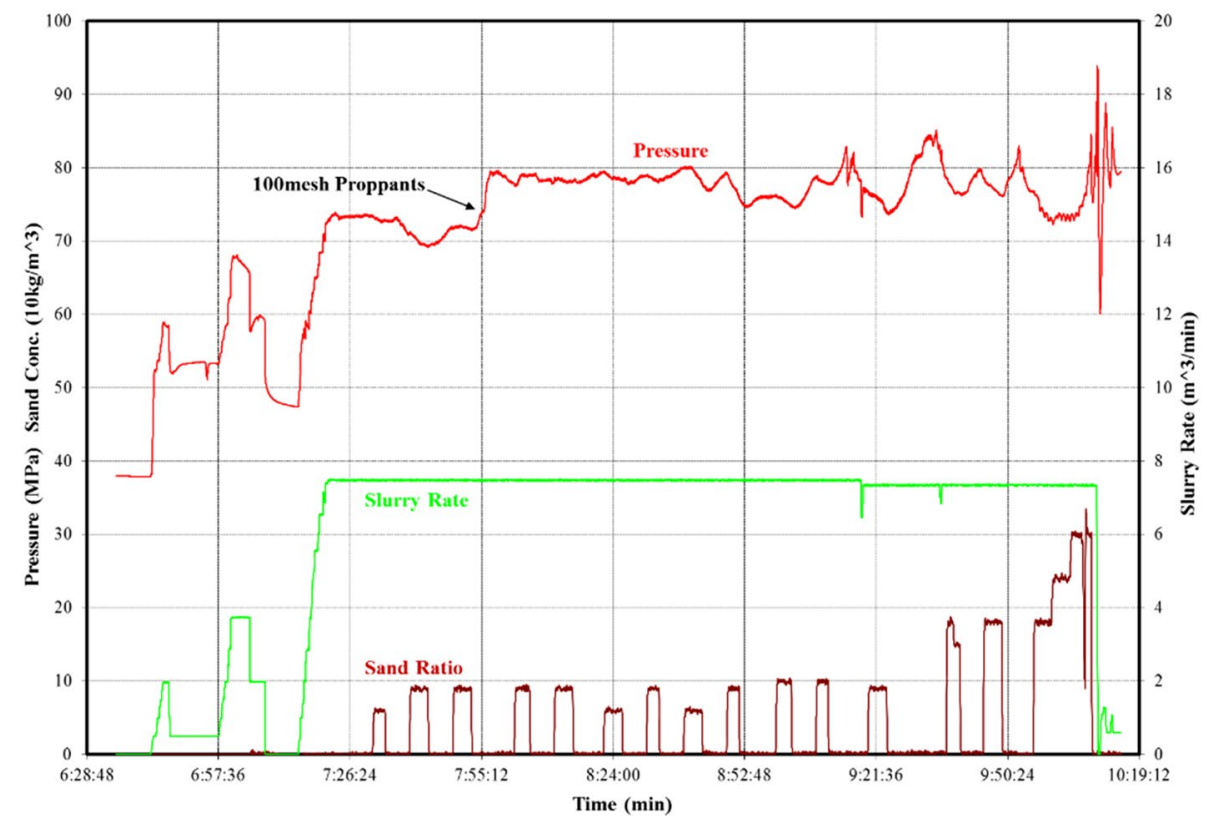

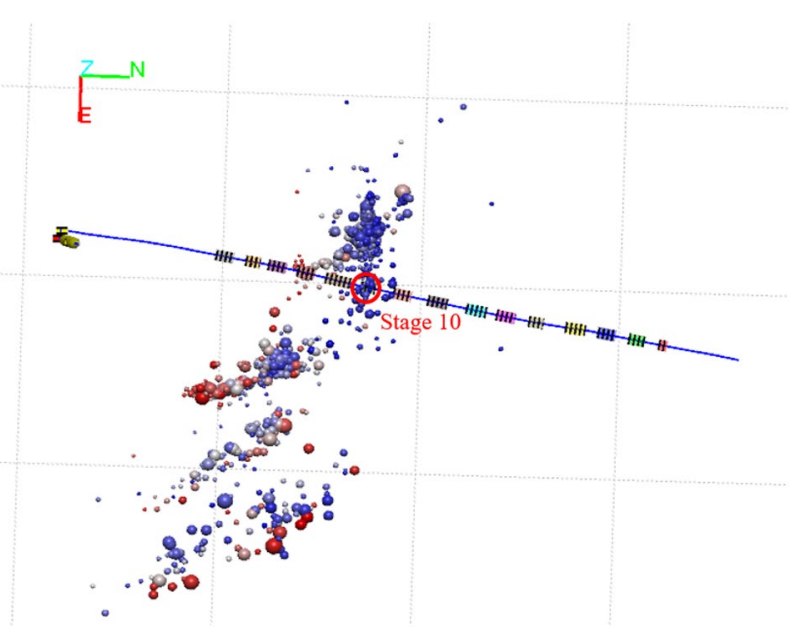

Fig. 8 Monitoring results of microseismic cracks of stage 10 (color code is displayed according to time)

fracturing, the microseismic signals generated by a rock fracture are collected and positioned to determine the location of the rock fracture, monitor underground rock fractures and their spatial distribution, and then on this basis, evaluate the fracturing effect. According to the Mohr-Coulomb criterion, the conditions of rock shear failure can be written as (Liu J et al. 2004):

$\tau \geq \tau_{0}+\frac{\mu\left[\left(\sigma_{1}+\sigma_{3}-2 P_{0}\right)+\left(\sigma_{1}-\sigma_{3}\right) \cos 2 \varphi\right]}{2}$

in which $\tau$ is the shear stress acting on the fracture plane; $\tau_{0}$ is the inherent shear strength of the rock; $\sigma_{1}$ and $\sigma_{2}$ are the maximum and minimum horizontal principal stress, respectively; $\mathrm{P}_{0}$ is the formation pressure; $\varphi$ is the angle between the maximum principal stress and the normal direction of the fracture plane; and $\mu$ is the internal friction coefficient of the rock. When $\tau$ satisfies the conditions of Equation (1), a microseismic event occurs.

At present, the type of microseismic monitoring used should be downhole monitoring, which is relatively welldeveloped in four aspects: precision, reliability, processing speed and equipment distribution. The downhole microseismic monitoring method places the detector into the adjacent well of the fracturing well and corrects the geophone direction and formation velocity model by receiving the perforation signal. Then, the source position of the fracturing microseismic event point is calculated according to the characteristics of the fracturing microseismic event and the corrected geophone direction and velocity model.

A total of 11437 microseismic events were processed and interpreted in this monitoring, and the microseismic signals were all within the scope of the monitoring instruments. The monitoring distance had a certain influence on the monitored quantity, but it was not the main factor. The cracks of this multistaged fracturing are generally divided into two parts: the fractures of stages 1-8 near the wellbore develop along the direction of $120^{\circ}$ azimuth (main fractures around the wellbore), with overall fracture dimensions of approximately 500 meters in length and approximately 400 meters in width (including natural fractures), and the number of seismic events is basically stable with a slowly rising trend. The start of stage 6 opened 500 meters away from the wellbore and gradually developed natural fracture zones in the limestone formation. Starting from stage 7, microseismic 
Fig. 9 Microseismic fracture monitoring results of well H1-1(top view)

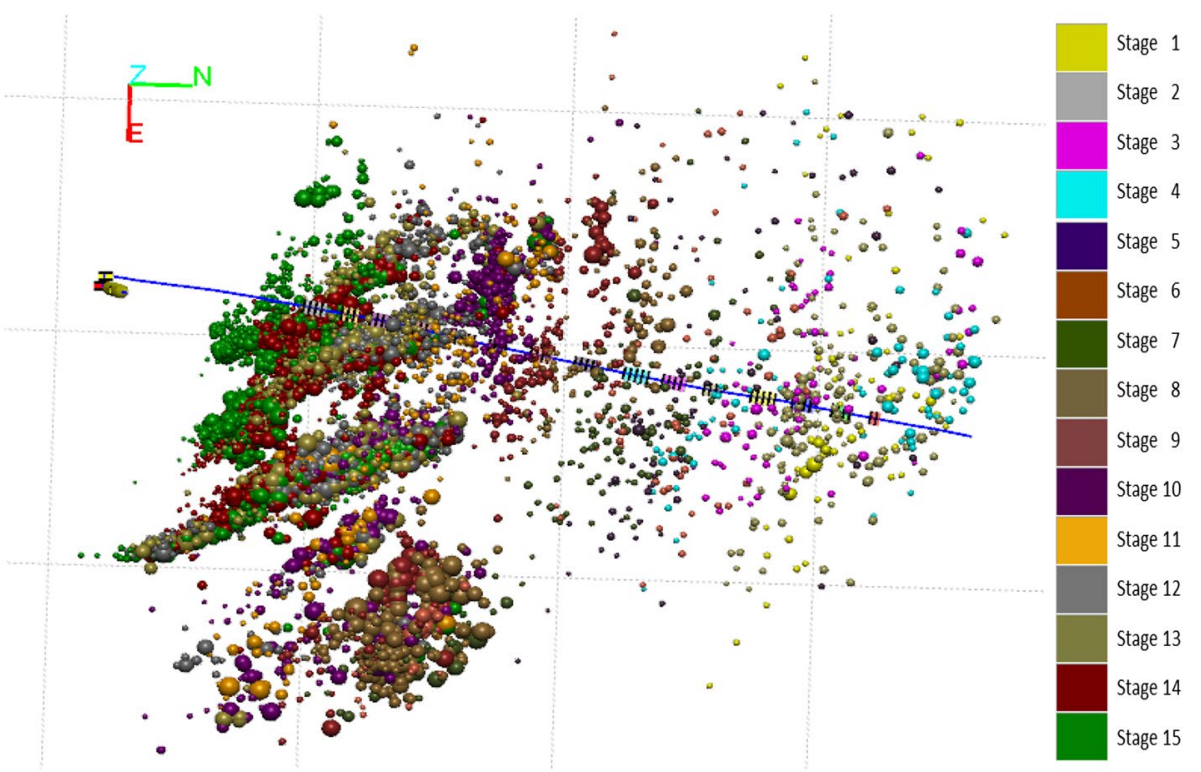

events showed a rapidly increasing trend, and the scale was further increased mainly via natural fractures. The hydraulic fractures gradually expanded to the limestone layer, and then developed further and extended around the wellbore. Eventually, five natural fracture zones were formed parallel to the azimuth angle of approximately $150^{\circ}$, and the overall fracture range was $550 \mathrm{~m}$ long and approximately $300 \mathrm{~m}$ wide (including the limestone layer). The SRV was approximately $1.9 \times 10^{7} \mathrm{~m}^{3}$.

\section{Results and analysis}

To evaluate the fracturing effect, the conventional method is to obtain accurate reservoir parameters and fracture parameters through a net pressure match (Liu GQ and Economides C. 2019). In the traditional theoretical model, the fracture is a biwing symmetrical fracture, which is created to improve the conductivity of the reservoir (Perkins T and Kern L. 1961). However, volume fracturing is widely used in shale gas exploration, and its initiation criterion, which is no longer tensile fracture initiation and propagation, does not fit the traditional classical model. In the process of fracture extension, hydraulic fractures communicate with natural fractures, eventually forming a complex fracture network (Bazan L and Meyer B. 2015). Because the pressure systems are complex due to the continuous opening of secondary fractures during the process, the conventional method of net pressure fitting to simulate fracture geometry is not suitable for post-frac evaluation in shale reservoirs. A new method for evaluating fracturing after frac is proposed in this paper: by considering the complex fracture network formed by the shale gas fracturing and taking the microseismic monitoring data (fracture parameters and the number of microseismic events) as constraint conditions, Mshale module, which is a discrete fracture network simulator designed for simulating three-dimensional hydraulic fracture propagation in multiple, cluster and discrete type fractures in shales and coal bed methane, is used and the engineering parameters in the actual fracturing process are combined to simulate fracturing (Meyer B and Bazan L. 2011).

The engineering parameters, including the operation parameters and pump schedule, are all fixed. Therefore, these are fixed input parameters in the post-frac simulation. For the net pressure match of shale gas, there are two main points that cause inconsistencies between the simulation results and the actual results (monitoring results): (1) The understanding of reservoir parameters (reservoir physical parameters and rock mechanics parameters) is inaccurate because they are similar to the simulation of a conventional reservoir; (2) the set parameters of the fracture network are inaccurate. Different fracture network parameters correspond to different SRV results. The fracture extension of microseismic monitoring is similar to the actual situation, where more frequent microseismic events correspond to a more complex fracture network. At the same time, the monitored fracture parameters (fracture length, width and height) have better credibility, so taking the microseismic data as constraints is more suitable for the fracturing simulation.

Based on the reservoir data for H1-1, well H1-3, which was located on the same platform, adopted the production logging test. Thus, production data of each stage can be obtained, and the relationship among production, microseismic events and SRV can be analyzed. More exact results can be achieved by using well H1-3 for the post-frac simulation. All stages of the well adopted the same fracturing design. To

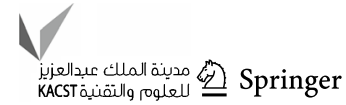


accurately evaluate the frac effect, the 7th and 17th stages of this well were selected for analysis in the fracturing simulation study. Both stages successfully completed the operation process without any accidents during the entire fracturing stage. Table 2 shows the main treatment parameters and monitoring data for stages 7 and 17 .

Based on the treatment data for stage 7, the Mshale model in the Meyer Software was used to simulate the fracture in this section, and the fracture parameters for microseismic monitoring were taken as constraints to fit the parameters in the model. Figure 10 shows the simulation results of the DFN model for stage 7. According to the results, the SRV of the entire fracture network is approximately $2.797 \times 10^{6}$ $\mathrm{m}^{3}$, the fracture length (the main + secondary fracture) is approximately $7747.4 \mathrm{~m}$, and the simulated fracture height is $33.4 \mathrm{~m}$. Since the microseismic monitoring results are based on the inversion of microseismic events and there are certain errors in the microseismic data, the fracture length and height determined by microseismic monitoring are generally higher, which is consistent with the understanding of field engineers.

Table 2 Treatment parameters and monitoring data of typical frac stages in well H1-3

\begin{tabular}{lll}
\hline Stage & $7 \#$ & $17 \#$ \\
\hline Perf Cluster & 3 & 3 \\
Perf Intervel(m) & 22,32 & 25,30 \\
Slurry $\left(\mathrm{m}^{3} / \mathrm{min}\right)$ & 9.0 & 9.6 \\
Fluid volume $\left(\mathrm{m}^{3}\right)$ & 1810 & 1500 \\
Sand (t) & 73.2 & 62.1 \\
ISIP(MPa) & 63 & 49 \\
Microseismic events & 339 & 6709 \\
Monitored fracture length $(\mathrm{m})$ & 353 & 408 \\
Monitored fracture height $(\mathrm{m})$ & 38 & 47 \\
Production $\left(\mathrm{m}^{3} / \mathrm{d}\right)$ & 3372 & 18951 \\
\hline
\end{tabular}

Similarly, based on the fracturing construction data of stage 17, this section was simulated in the Mshale module. Figure 11 shows the fracture simulation results of the DFN fracturing model for the 17th stage. According to the simulation results, the reconstructed volume of the entire fracture network is approximately $6.054 \times 10^{6} \mathrm{~m}^{3}$, the fracture length (the main fracture and secondary seam) is approximately $13285 \mathrm{~m}$, and the simulated fracture height is $42.6 \mathrm{~m}$.

According to the above simulation results, it is easy to see that: (1) The frac scale of stage 7 is larger than that of stage 17 , but the final production is far less than that of stage 17 , indicating that when the frac scale reaches a certain degree, it is no longer the key parameter in determining the fracturing effect. (2) The number of microseismic events can reflect the communication between the natural and artificial fractures in the extension process. For better stimulation results, there are secondary fractures opening constantly during the fracturing process, so the number of corresponding microseismic events is supposed to be greater. (3) The SRV of the two stages is $2.791 \times 10^{6} \mathrm{~m}^{3}$ and $6.054 \times 10^{6} \mathrm{~m}^{3}$, respectively, and the corresponding production logging results are $3372 \mathrm{~m}^{3} / \mathrm{d}$ and $1895 \mathrm{~m}^{3} / \mathrm{d}$, which are in good agreement and indicate that the simulation results are consistent with the actual frac effects in the field.

Based on the above results, the treatment parameters are optimized based on the original frac design as follows: (1) Space refinement. The interval between each cluster is reduced from $60-80$ to $50-70 \mathrm{~m}$. (2) Increase the frac scale if possible. The fluid volume per stage expands from $1600-2000$ to $1800-2200 \mathrm{~m}^{3}$. The amount of sand per stage is increased from $45-90$ to $80-120$ t. (3) Increase the slurry rate from $8-10 \mathrm{~m}^{3} / \mathrm{min}$ to the current $10-12 \mathrm{~m}^{3} /$ min. For those wells with low treatment pressure, improving the displacement may lead to good performance after volume fracturing.
Fig. 10 Simulation result of stage 7 based on DFN model

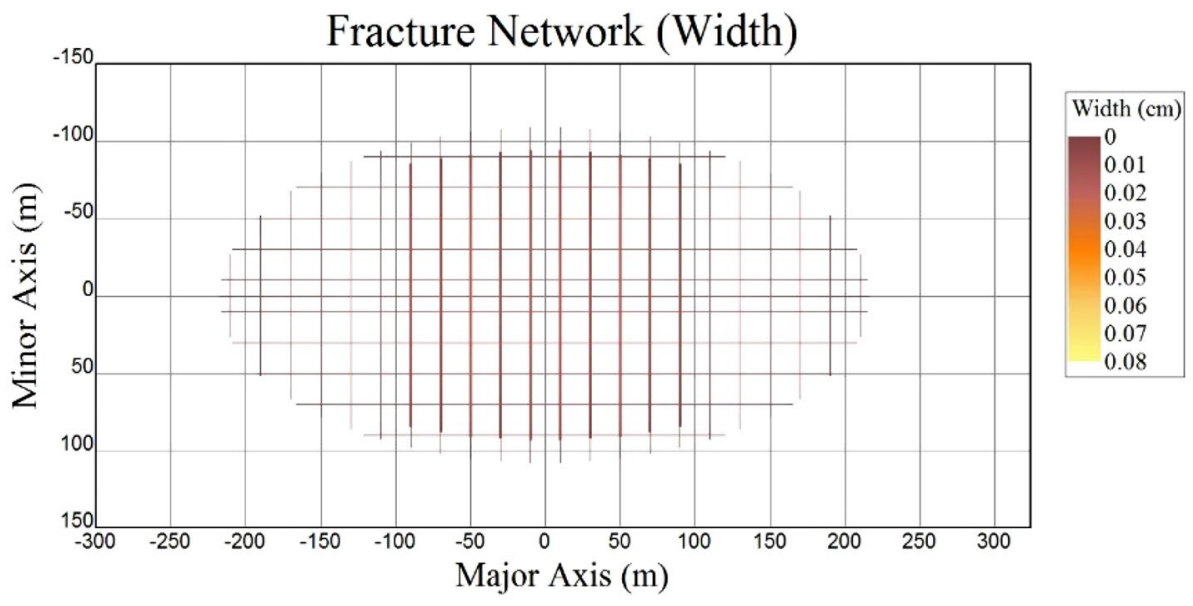


Fig. 11 Simulation result of stage 17 based on DFN model

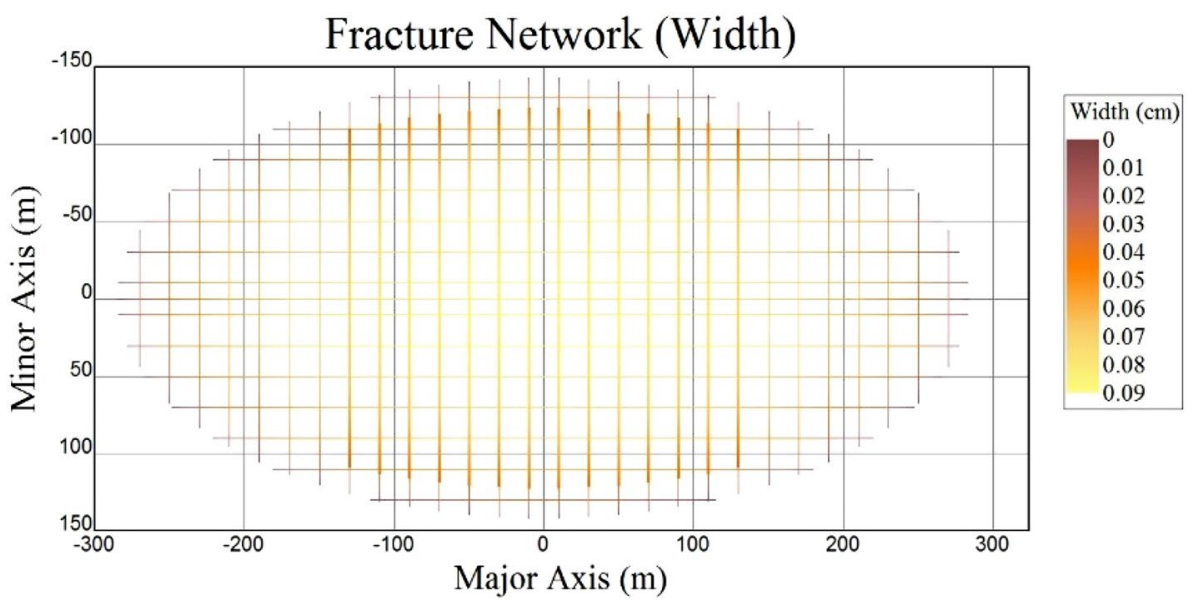

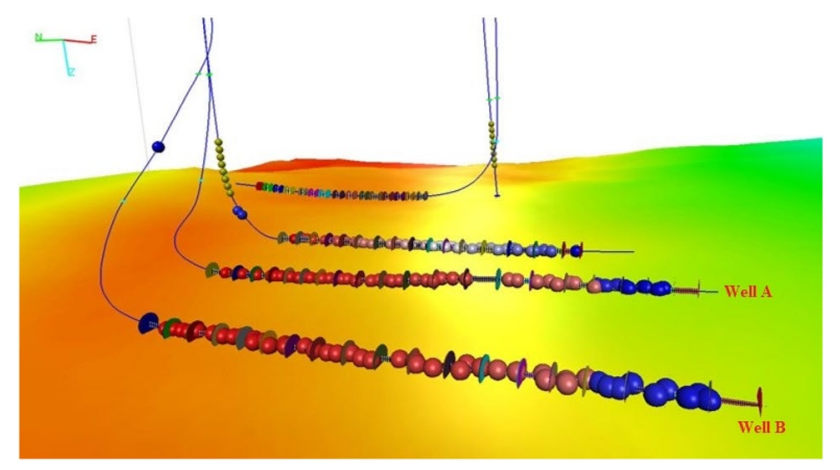

Fig. 12 Location sketch map of Well A and Well B

\section{Case study}

As shown in Fig 12, two shale gas wells, well A and well B in the YS Block, are located on the same platform. The horizontal length, fracturing stages and frac pressure are relatively close. The treatment parameters of the two wells are shown in Table 3. The fracturing design of well B follows the new method proposed by the author, while that of well A follows the conventional method. According to the new fracturing design method, the interval distance is shortened, small spacing cluster perforations are used for fracturing, and the frac scale is increased appropriately with fluid volumes up to 1800 $\mathrm{m}^{3} /$ stage and sand amounts up to $80-120 \mathrm{t} / \mathrm{stage}$; then, according to the operation pressure, the slurry is increased $\left(>10 \mathrm{~m}^{3} /\right.$ $\mathrm{min}$ ). The production of wells B and A for one month after frac is $10.13 \times 10^{4} \mathrm{~m}^{3} / \mathrm{d}$ and $8.83 \times 10^{4} \mathrm{~m}^{3} / \mathrm{d}$, respectively, with well
B showing an increase of approximately $14.7 \%$ compared to well A. Thus, the post-frac production of the shale gas wells is significantly improved by the new method.

\section{Conclusion}

To present a novel and optimal frac design method for shale gas wells, this study takes the Zhao Tong National Shale Gas Demonstration Zone in China as an example. Based on the microseismic data and field data, some typical fracturing treatment procedures were analyzed. The fracturing was simulated using the DFN model, and the microseismic monitoring fracture parameters were considered as constraints. According to the simulation results, an improved fracturing design was proposed and the well production after frac was used to evaluate the quality of the treatment. The main conclusions are as follows:

(1) Microseismic monitoring data can effectively reflect the post-frac effects. More microseismic events show more frequent communication between the hydraulic fractures and natural fractures; thus, a more complex fracture network is eventually created. More microseismic events also indicate that the effective SRV is larger.

(2) According to the post-frac simulation results, the original fracturing design was improved by adopting a multistaged fracturing mode with small distance, increasing the fracturing scale (sand amount and fluid volume per stage) under the pressure limit, and increasing the pump rate to provide sufficient energy.
Table 3 Treatment parameters of Well A and Well B

\begin{tabular}{|c|c|c|c|c|c|c|}
\hline Well & Stage & Interval(m) & Fluid/stage $\left(\mathrm{m}^{3}\right)$ & Sand/stage(t) & Slurry $\left(\mathrm{m}^{3} / \mathrm{min}\right)$ & Production $\left(\times 10^{4} \mathrm{~m}^{3} / \mathrm{d}\right)$ \\
\hline A & 19 & 75.8 & 1817.8 & 47.8 & 9.9 & 8.83 \\
\hline B & 19 & 57.5 & 1821.5 & 80.5 & 11.4 & 10.13 \\
\hline
\end{tabular}


(3) Two wells were tested on the same platform using the traditional frac design and the improved design method. The daily production of the new method after frac was $10.13 \times 10^{4} \mathrm{~m}^{3} / \mathrm{d}$, which was $14.7 \%$ greater compared with the $8.83 \times 10^{4} \mathrm{~m}^{3} / \mathrm{d}$ produced by using the traditional method.

The case study shows that the new optimal design method can improve the post-frac production of shale gas wells. It is of great significance in guiding the design of shale fracturing.

Funding This study was funded by the Project of the State Key Laboratory of Shale Oil and Gas Enrichment Mechanisms and Effective Development under grant no.10010099-19-ZC0607-0042, the Project of the Key Laboratory of Well Stability and Fluid \& Rock Mechanics in Oil and Gas Reservoir of Shaanxi Province, Xi' an Shiyou University under grant no.WSFRM20190302001, the Project of Shandong Provincial Key Laboratory of Depositional Mineralization \& Sedimentary Mineral under grant no. DMSM2019001.

Open Access This article is licensed under a Creative Commons Attribution 4.0 International License, which permits use, sharing, adaptation, distribution and reproduction in any medium or format, as long as you give appropriate credit to the original author(s) and the source, provide a link to the Creative Commons licence, and indicate if changes were made. The images or other third party material in this article are included in the article's Creative Commons licence, unless indicated otherwise in a credit line to the material. If material is not included in the article's Creative Commons licence and your intended use is not permitted by statutory regulation or exceeds the permitted use, you will need to obtain permission directly from the copyright holder. To view a copy of this licence, visit http://creativecommons.org/licenses/by/4.0/.

\section{Reference}

Bazan LW, Meyer BR (2015) Fracture complexity: analysis methodology and signature pressure behavior of hydraulic fracture propagation from horizontal wellbores. In: SPE Asia Pacific Unconventional Resources Conference and Exhibition, 9-11 November, Brisbane, Australia

Cheng YM (2012) Mechanical interaction of multiple fracturesexploring impacts of the selection of the spacing/number of perforation clusters on horizontal shale-gas wells. SPE J 17(4):992-1001

Cheng YF, Dong BX, Shi X et al (2012) Seepage mechanism of a triple-porosity/dual permeability model. Natl Gas Ind 32(9):44-47
Enriquez TO, Knorr A, Zhu D et al (2019) Relationships between mechanical properties and fracturing conductivity for the Eagle Ford Shale. SPE Prod Op 34(2):318-331

Ge J, Ghassemi A (2011) Permeability enhancement in shale gas reservoirs after stimulation by hydraulic fracturing. In: 45th U.S. Rock Mechanics/Geomechanics Symposium, San Francisco, California, USA

Guo JC, Lu QL, Zhu HY et al (2015) Perforating cluster space optimization method of horizontal well multi-stage fracturing in extremely thick unconventional gas reservoir. J Natl Gas Sci Eng 26:1648-1662

Liang X, Xu JB, Liu C et al (2019) Geosteering technology based on geological and engineering integration for horizontal wells in Zhaotong national shale gas demonstration zone. China Petrol Exp 24(02):226-232

Liu GQ, Economides CA (2019) Consistent model for injection and falloff pressure match of diagnostic fracture injection tests (DFITs). SPE Drill Complet 34(04):345-355

Liu JZ, Wang CY, Liu JM et al (2004) Micro-seismic monitor on the operation of oil fields. Petrol Exp Develop 31(02):71-73

Liu SY, Zhang YX, Lou YS et al (2018) Novel evaluation approach for shale brittleness index. DYNA 93(4):442-447

Luo X, Wang YG, Li J et al (2018) Geosteering technology for complex geological conditions at Zhaotong Shale gas development demonstration area. Drill Prod Technol 41(3):29-32

Meyer BR, Bazan LW (2011) A discrete fracture network model for hydraulically induced fractures-theory, parametric and case studies. In: SPE Hydraulic Fracturing Technology Conference, 24-26 January, The Woodlands, Texas, USA

Pan LH, Zhang SC, Cheng LJ et al (2014) A numerical simulation of the inter-cluster interference in multi-cluster staged fracking for horizontal wells. Natl Gas Ind 34(1):74-79

Perkins TK, Kern LR (1961) Widths of hydraulic fractures. J Petrol Technol 13(9):937-949

Rascon EU, Yousefzadeh A, Virués CJ et al (2018) Evolution and evaluation of SRV in shale gas reservoirs: an application in the horn river shale of Canada. SPE Reserv Eval Eng 21(4):889-906

Roussel NP, Sharma MM (2011) Optimizing fracture spacing and sequencing in horizontal-well fracturing. SPE Prod Operat 26(2):173-184

Warpinski NR, Mayerhofer MJ, Vincent MC et al (2009) Stimulating unconventional reservoirs: maximizing network growth while optimizing fracture conductivity. J Can Petrol Technol 48(10):39-51

Wu Q, Xu Y, Wang XQ et al (2012) Volume fracturing technology of unconventional reservoirs: connotation, optimization design and implementation. Petrol Exp Develop 39:377-384

Publisher's Note Springer Nature remains neutral with regard to jurisdictional claims in published maps and institutional affiliations. 